\title{
Astronauts in outer space teaching students science: comparing Chinese and American implementations of space-to-earth virtual classrooms
}

\author{
Song A. An ${ }^{1}$, Meilan Zhang ${ }^{1}$, Daniel A. Tillman ${ }^{1}$, William Robertson ${ }^{1}$, Annette Siemssen ${ }^{1}$ and \\ Carlos R. Paez ${ }^{2}$ \\ ${ }^{1}$ Department of Teacher Education, University of Texas at El Paso, El Paso, U.S.A. \\ ${ }^{2}$ School of Engineering, Math, \& Technology, Navajo Technical University, Crownpoint, U.S.A. \\ For correspondence: saan@utep.edu
}

\begin{abstract}
The purpose of this study was to investigate differences between science lessons taught by Chinese astronauts in a space shuttle and those taught by American astronauts in a space shuttle, both of whom conducted experiments and demonstrations of science activities in a microgravity space environment. The study examined the instructional structure and science topics coverage, as well as the methods employed for helping students conceptualize scientific laws via experimental demonstrations and activities. The analysis of the lessons sampled in this study revealed three predominant themes for how both the Chinese and the American astronauts conceptualized the science topics (i.e., Health and Life in Space, Work and Career in Space, and Exploration in Space and Earth Science). The analysis also examined how the teacher-student interactions were structured. Research findings suggest that under the appropriate conditions informal science education can play a distinct role in providing students with experiences of: (a) experiments unavailable in classroom settings, and (b) explanations of these experiments by field-based scientists conducting original research.
\end{abstract}

Keywords: science education, international comparison, informal education, instructional designs

\section{Introduction}

International comparisons are increasingly a widespread research theme in science, technology, engineering, and mathematics [STEM] education. One of the reasons is that STEM education in different countries is strongly influenced by cultural and social factors that shape goals, beliefs, expectations, and teaching method (An, Kulm \& Wu, 2002), and cross-cultural comparison can help researchers and educators explicitly recognize and understand their own implicit theories about how teachers teach and how students learn (Stigler \& Perry, 1988). It is commonly presumed that classroom instruction is one of the key sources from which students learn educational content, and therefore the pedagogical styles used during formal educational processes can have a prominent impact on students' learning outcomes (Apple, 2014). Within published research studies, Chinese versus U.S. mathematics and science education have been contrasted in a variety of ways, including: (a) teachers' beliefs and efficacy (e.g., Correa, Perry, Sims, Miller, \& Fang 2008); (b) teachers' content and pedagogical knowledge (e.g., An, Kulm, \& Wu, 2004); (c) students' achievement and abilities (e.g., Lan, Legare, Ponitz, Li, \& Morrison, 2011); (d) student's attitudes and confidence levels (e.g., Chen \& Stevenson, 1995); (e) textbooks and curriculums (e.g., Cai, Lo, \& Watanabe, 2002); and (f) lesson implementations and instructional designs (e.g., An, 2008; Cai, \& Lester, 2005;). However, most of these published studies were focused on teaching and learning in formal classroom settings, while only a limited set of studies have investigated out-of-school learning opportunities between students from different counties. As Wang and Lin (2005) indicated, the fact that Chinese students performed 
better in STEM achievement than U.S. students cannot be credited solely to formal schooling and teaching processes; instead, many other factors such as informal learning opportunities including hidden and extra-curricular activities should be examined. The current study was undertaken to help fill the research gap about differences between the two countries regarding informal science education.

\section{Literature Review}

Research examining out-of-school science learning environments has a long history that can be traced back to the 1950s, when the U.S. federal government promoted science education by funding numerous science centers and science education research projects during the post-Sputnik era with the goal encouraging the development of science professionals (Schiele, 1995; Scribner \& Cole, 1973). There are multiple varieties of non-classroom settings that have been identified as providing students with opportunities to experience science pedagogy via open-inquiry and meaningful contextualization (Faria, Pereira, \&Chagas, 2012; Griffin, 2004). Previous empirical studies have shown that structured science education programs that occur within informal (i.e., non-classroom) settings can positively motivate students' science interest, enhance their science knowledge, and expand their sense of future science career options (Falk \&Storksdieck, 2010). To enhance school curriculum, classroom teachers can provide students with lessons that feature learning opportunities designed to occur in out-of-classroom settings as a way to helps students (re)cover and (re)conceptualize science subject matter (DeWitt \&Storksdieck, 2008; Gutwill\& Allen, 2012).

By immersing students in a learning approach that utilizes engaging and relatable methods of content delivery that appeal to both the affective and academic aspects of STEM, the process skills and overall content knowledge of the students have the potential to greatly increase. Studies have shown that students who are involved in active science learning in meaningful informal contexts acquire knowledge and become proficient in problem solving (Robertson \& Lesser, 2013). This model of informal learning turns everyday objects, such as cell phones, tablets, community engagement opportunities, and informational websites replete with STEM content, into tools for STEM learning for teachers, students, mentors and parents. Traditionally, informal STEM learning is limited to onetime visits to a designed setting by school groups, individuals, or families. As a result of this approach, students are more often disengaging from STEM content areas due to the lack of connection and meaning to their own lives (Osborne, Simon, \& Collins, 2003). As such, it is particularly important that science be culturally relevant for all youth, which means, "not only learning about the lives of [culturally and linguistically diverse] students, but learning from them as well" (Boutte, Kelly-Jackson, \& Johnson, 2010, p. 4).

For education to be fundamentally transformative, the traditional teacher/student relationship needs to changes and the mechanism for learning needs to extend as well outside of the classroom. The perspective of the teacher delivering content to passive students must be discarded, as teachers, community members and parents must extend themselves as respectful guides and compassionate helpers who grant students the opportunities to become actively involved in their own learning and in classroom operations (Hasslen, 2008). As change agents, educators need to engage their students in active learning projects that require them to interact with individuals outside the school, which in turn establishes links within their communities (Donovan, 2002). For the teacher, adopting a transformative education approach can facilitate informal learning assignments and resources that can take place in different venues and not solely in the classroom (Palmer, 1998).

Advocates of informal science education have proposed that the curriculum delivered in K-12 schools should be made relevant to students' authentic interests by employing meaningful projects about grade-appropriate phenomena-such as educational activities developed based on student-friendly 
informal learning settings (e.g., zoos, museums, planetariums, aquariums, and botanical gardens) offering students opportunities to construct knowledge regarding topics that are meaningful to them (Braund\& Reiss, 2006). Previous published research has recognized student benefits from informal science education, including: (1) students developing scientific ideas and understanding science processes through peer collaborations (Eshach, 2007; Palmquist\& Crowley, 2007); (2) providing students with a meaningful context to appropriate the scientific vocabulary and become familiar with the community of science practitioners (Brossard, Lewenstein, \& Bonney, 2005; Haden et al., 2014); and (3) inspiring students' interest and excitement about science and developing a positive belief towards STEM subjects and careers (Jarvis \& Pell, 2005; Jones, Scanlon, \& Clough, 2013).

The purpose of this study was to investigate differences between science lessons taught by Chinese astronauts in a space shuttle and those taught by American astronauts in a space shuttle, both of whom conducted experiments and demonstrations of science activities in a microgravity space environment. Specifically, this study was designed to complement already existing cross-national studies comparing Chinese and American STEM education pedagogical approaches including conceptualizing, experimenting, and representing science concepts in non-traditional environments. The current study examined the instructional structure and science topics coverage, as well as the methods employed for helping students conceptualize scientific laws via experimental demonstrations and activities. The three research questions that the study was designed to address were: (a) How instructional structures were organized between the lessons taught by Chinese and American astronaut-teachers? (b) How science topics were conceptualized across the lessons taught by Chinese and American astronaut-teachers? (c) How the Chinese and American astronaut-teachers conducted experiments in the microgravity environment to help students understand the scientific concepts being taught?

\section{Methods}

Background of Assessed Lessons

Via a purposeful sampling method, the lessons selected for analysis were all taught by American or Chinese astronaut-teachers while orbiting in space shuttles employing live communication with students and teachers located in classrooms from their respective countries. These lessons were selected because they illustrated innovative science pedagogy, particularly the utilization of alternative (i.e., non-classroom) settings for engaging place-based science lessons. The video lessons selected were then examined scene-by-scene to identify and code the science pedagogy interactions between the students and teachers on the ground, and the astronaut-teachers communicating from a space shuttle orbiting in outer space. Table 1 presents an overview of the Chinese and American space lessons that were analyzed, including the number of students and teachers involved, as well as the educational technologies employed.

Table 1Overview of the Chinese and American Space Lessons

\begin{tabular}{ccccc}
\hline \multirow{2}{*}{$\begin{array}{c}\text { Students } \\
\text { and } \\
\text { Teachers }\end{array}$} & Number of students in the ground classroom & $\begin{array}{c}\text { Chinese } \\
\text { Lesson }\end{array}$ & $\begin{array}{c}\text { American } \\
\text { Lesson 1 }\end{array}$ & $\begin{array}{c}\text { American } \\
\text { Lesson 2 }\end{array}$ \\
\hline \multirow{5}{*}{ Number of teachers in the space classroom } & 330 & 20 & 23 \\
& Number of teachers in the ground classroom & 2 & 6 & 2 \\
& Number of broader audiences & $60,000,000$ & N/A & 6 \\
& Number of cameras in space shuttle & 2 & 1 & N/A \\
\hline & Number of cameras in ground classroom & 3 & 0 & 2 \\
Educational & Two-way video communication devices & Available & N/A & N/A \\
\cline { 2 - 5 } & Two-way audio communication devices & Available & Available & Available \\
& Multiple shot transitions & Available & N/A & Available
\end{tabular}




\begin{tabular}{|c|c|c|c|c|}
\hline \multirow[t]{4}{*}{ Technology } & Double screen & Available & N/A & Available \\
\hline & Video edited based on exact copy of live feed & Available & N/A & Available \\
\hline & $\begin{array}{l}\text { Video had titles/subtitles/credits/graphics } \\
\text { added }\end{array}$ & Available & N/A & Available \\
\hline & Live broadcasting & Available & N/A & Available \\
\hline
\end{tabular}

The Chinese lesson was co-funded by the Ministry of Education of the People's Republic of China (MEPRC), China Manned Space Engineering Office (CMSEO) and China Association for Science and Technology (CAST). The space-based classroom of the Chinese lesson was in the space shuttle Shenzhou during the mission Shenzhou 10, which was launched on June 11, 2013 in the Jiuquan Satellite Launch Center, Inner Mongolia, China and landed on June 26, 2013, in Siziwang Banner Shuttle Landing Facility, Inner Mongolia, China. The Shenzhou space shuttle was orbiting at the low earth regime with a perigee of 330 kilometers and apogee of 210 kilometers. The leading teacher in the space-based classroom was a female crewmember Yaping Wang, the supporting teachers in the space-based classroom were the commander HaishengNie, and the other crewmember Xiaoguang Zhang who served as the cameraman for the lesson. The ground-based classroom of the Chinese space lesson was located in an auditorium at one of local middle-high schools in Beijing, China, and around 330 middle and high school students were selected to participate in the lesson. The two teachers (Ms. Yi Shi and Mr. Qi Bi) in the ground classroom were each science teachers from local middle/high schools. The ground-based classroom was equipped with two-way video and audio communication devices, which allowed students to interact with the astronaut-teachers in the Shenzhou space shuttle. Moreover, Chinese Central Television-which is the principal television broadcaster in China-live broadcasted the lesson, resulting in more than 60 million middle and high school students across China watching the live lesson (as was required that year by the national Chinese education curriculum).

The American lessons were funded by the National Aeronautics and Space Administration (NASA). The space-based classroom of the American lessons was in the space shuttle Endeavour during the mission STS-118, which was launched on August 8, 2007 in the Kennedy Space Center, Florida, United States, and landed on August 21, 2007, in Kennedy Space Shuttle Landing Facility, Florida, United States. The Endeavour space shuttle was orbiting at the low earth regime with both perigee and apogee of 226 kilometers. The leading astronaut-teacher in the space classroom in the first American lesson was female crewmember Barbara Morgan, and the supporting teachers in the American space-based classroom included the three mission specialists Clay Anderson, Alvin Drew, and Dafydd Williams. Barbara Morgan was the leading astronaut-teacher again in the second American lesson, while the supporting teacher was mission specialist Alvin Drew. The ground-based classrooms of the American space lessons were located in: (1) Discovery Center, Boise, Idaho; and (2) Challenger Center, Alexandria, Virginia. In total, 43 upper elementary and middle school students were selected to participate in the lessons by asking astronaut-teachers questions. Specifically, there were 20 students in the Discovery Center and 23 students in the Challenger Center. Joyce Winterton (NASA assistant administrator for education); June Rodgers (Challenger Center chairman emeritus); Joseph Allen (chairman of Challenger Center for space science education); William Readdy (secretary of Challenger Center for space science education) and Roger Crouch (former astronaut NASA space shuttle) served as the ground-based classroom teachers in the Challenger Center. Both ground-based classrooms were equipped with one-way video and two-way audio communication devices, which allowed students to interact with the astronaut-teachers in the Endeavour space shuttle. Although non-attending American students were not required to watch the live lesson, they live lessons were broadcast by multiple local television stations, and the lesson videos were disseminated online for American teachers and students to employ as free learning resources. 


\section{Data Analysis}

The rationale for the lesson analysis was based upon the concepts Wang and Murphy (2004) proposed regarding effective lessons. They noted that lessons that generally performed well included sufficient: (1) lesson content linkages (e.g., causally linked and logically arranged pedagogical events), and (2) pedagogical process organizations (e.g., meaningful discourse around target lesson topics between students and teachers). Based on a revised version of the coding framework used in the TIMSS video study (Roth et al., 2006), the coding processes that the current research team employed had three facets (see table 2), such that the classified lessons were coded by categorizing each identified video segment into descriptive themes defined by: (A) the instructional structures, (B) the classroom discourse, and $(\mathrm{C})$ the science topics coverage.

Table 2.Lesson coding aspects and specified coding tasks

\begin{tabular}{|c|c|}
\hline Aspects & Specified Coding Tasks \\
\hline \multirow{5}{*}{$\begin{array}{l}\text { Science topic } \\
\text { coverage }\end{array}$} & Identify the topic that was verbally explained with no visual representations \\
\hline & $\begin{array}{l}\text { Identify the topic that was introduced with visual representations and verbal } \\
\text { explanation }\end{array}$ \\
\hline & $\begin{array}{l}\text { Identify the topic that had space demonstrations with no comparative } \\
\text { demonstrations }\end{array}$ \\
\hline & Identify the topic that had space demonstrations with comparative demonstrations \\
\hline & $\begin{array}{l}\text { Identify the topic that had demonstrations in space with comparative } \\
\text { demonstrations on the ground }\end{array}$ \\
\hline \multirow{6}{*}{$\begin{array}{l}\text { Classroom } \\
\text { discourse }\end{array}$} & Identify the distribution of words spoken by teachers and students \\
\hline & Identify the number of questions the space teacher asked \\
\hline & Identify the number of questions the ground teacher asked \\
\hline & Identify the number of questions the students asked \\
\hline & Identify the number of questions the students answered \\
\hline & Identify the number of questions the students answered \\
\hline \multirow{5}{*}{$\begin{array}{l}\text { Instructional } \\
\text { structures }\end{array}$} & how students interact with space teachers \\
\hline & how students interact with ground teachers \\
\hline & how teachers asked questions based upon students' questions \\
\hline & how teachers interacted with other teachers \\
\hline & $\begin{array}{l}\text { how science demonstrations were used as a way to elicit students to ask questions } \\
\text { and answer questions }\end{array}$ \\
\hline
\end{tabular}

Specifically, regarding examining the science topics coverage the coding process firstly decomposed and categorized all the teaching units with distinct educational foci into generalized themes (e.g., health and life in space) and specified themes (e.g., techniques for preventing microgravity harms); then identified the level of instructional approach from lowest level (e.g., conceptualize a science concept through oral explanations) to the highest level (e.g., conceptualize a science concept through demonstrations in space with comparative demonstrations on the ground).

For examining the instructional structures within the selected lessons, the coding identified the manners in which the directions for teacher-student interactions included (1) how students and teachers asked and answered questions to each other, (2) how teachers interacted with other teachers, and (3) how science demonstrations were used as a way to elicit students to ask questions and answer questions. For examining the classroom discourses within the selected lessons, the coding that quantified the teacher-student interactions included (1) the number of questions that students and teachers asked as well as the number of questions they answered questions to each other, and (2) the distribution of words spoken by each group of teachers and students. 
All video lessons selected for this study were analyzed in their original languages and then translated into English for further coding processes. The video data were iteratively analyzed by four researchers (two Chinese native speakers, and two English native speakers) who coded data independently, who then later compared the coded data to resolve any inconsistencies collectively through discussions. Specifically, the video segments were first reviewed and coded by two teams of researchers (one Chinese native speakers and one English native speakers in each team) independently using a coding rubric that had been co-developed by the research team, and then the coding results were compared and the inter-rater agreement was $97.6 \%$. Inconsistent coding findings were then revised and re-coded by the group cooperatively.

\section{Results}

The analysis of the sampled science lessons taught by Chinese and American astronaut-teachers demonstrated both similarities and differences in science lesson structures and topics coverage. For similarities in lesson structures, both the Chinese lesson and American lessons were generally teacher-dominated discussions during which the majority of lesson time was utilized for presenting teachers' explanations and demonstrations rather than presenting students' explorations, explanations, or discussions. For similarities in topics coverage, both the Chinese lesson and American lessons covered a variety of parallel scientific concepts including astronauts' exploring space, performing micro-gravity experiments in space, studying earth science from space, staying healthy in space, working in space, and having a career in space. For differences in lesson structures, the Chinese teachers presented different behavioristic choices from their American peers in that the Chinese lesson employed two-way video interactions between ground-based students and spacebased astronaut-teachers while the American lessons employed only one-way video interactions between space-based astronaut-teachers (that were visible to the ground-based students) and groundbased students and teachers (that were not visible to the space-based astronaut-teachers). The next three sections provide more detailed comparisons between the Chinese and American lessons on lesson structures and science topics coverage and pedagogy.

\section{Instructional Structures}

To investigate the lesson structures employed, interactions were analyzed as to how instruction unfolded in terms of the interactions among the students and the teachers located at ground-based learning environments with the astronaut-teachers located at space-based environments. Generally, the instructional structures of the American lessons had less layers than the Chinese lesson, and the interactions within the two American lessons did not involve student-teacher discussions, but instead a student would ask a question and then a teacher would respond, often with an answer that included a demonstration addressing the students' question. Of the lessons analyzed, the American lesson that took place in the Discovery Center had the most conventional format in terms of lesson structures, containing only interactions between ground-based students and space-based astronautteachers, but with no intermediation by ground-based teachers. The American lesson in the Challenger Center had more tiers of interactions to the lesson structure, in that both space-based astronaut-teachers and ground-based teachers were involved in the instructional process of providing answers to the students' questions. In contrast, the Chinese lesson had the most complicated lesson structure among the three lessons. The Chinese lesson contained multi-way interactions among the ground-based students, the ground-based teachers, and the space-based astronaut-teachers. Additionally, both the ground-based teachers and space-based astronaut-teachers in the Chinese lesson participated in asking the ground-based students' questions that the students would answer as a pedagogical prompt for introducing the scientific concepts being taught. Figures 1-3 present diagrammatic representations of the instructional structures of the lessons analyzed. 
Questions and answers were also analyzed to examine the quality of interactions between the teachers and students that participated in the American and Chinese lessons. The findings of the analysis demonstrated that the two American lessons not only provided more opportunities for students to ask questions but also often involved more than one teacher responding to answer a student's question, whereas in the Chinese lessons it was usually a single teacher that would respond to answer a student's question. For example, students in the Discovery Center asked 20 questions and students in the Challenge Center asked 22 questions, whereas students in the Chinese lesson only asked 5 questions. For the questions that students asked in the American lessons, on average two teachers participated in answering each question posed by a student, while in the Chinese lesson on average only one teacher participated in answering each question posed by a student. Specifically, for the questions that American students asked in the Discovery Center, teachers offered 36 answers in total (with a question-to-answer ratio of 1:1.80); for the questions that American students asked in the Challenge Center, teachers offered 39 answers in total (with a question-to-answer ratio of 1:1.77); for the questions that students asked in the Chinese lesson, teachers offered 7 answers in total (with a question-to-answer-question rate of 1:1.40). The Chinese lesson was also different from the two American lessons in that none of the teachers asked questions to the students, instead only the students asked questions to the teachers; whereas in the Chinese lesson the teachers asked eight questions to the students and eight answers were received from the students in total (with a questionto-answer ratio of 1:1.00).

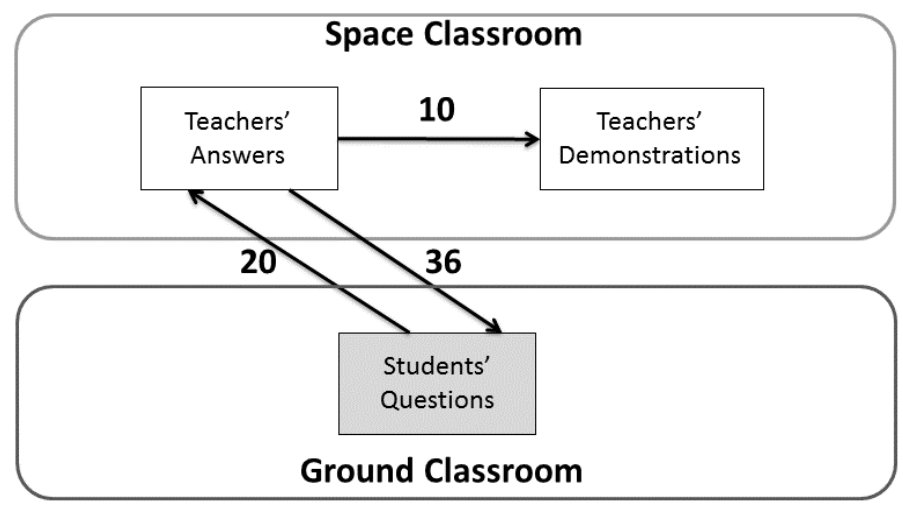

Figure 1: Instructional structure of American space lesson in Discovery Center.

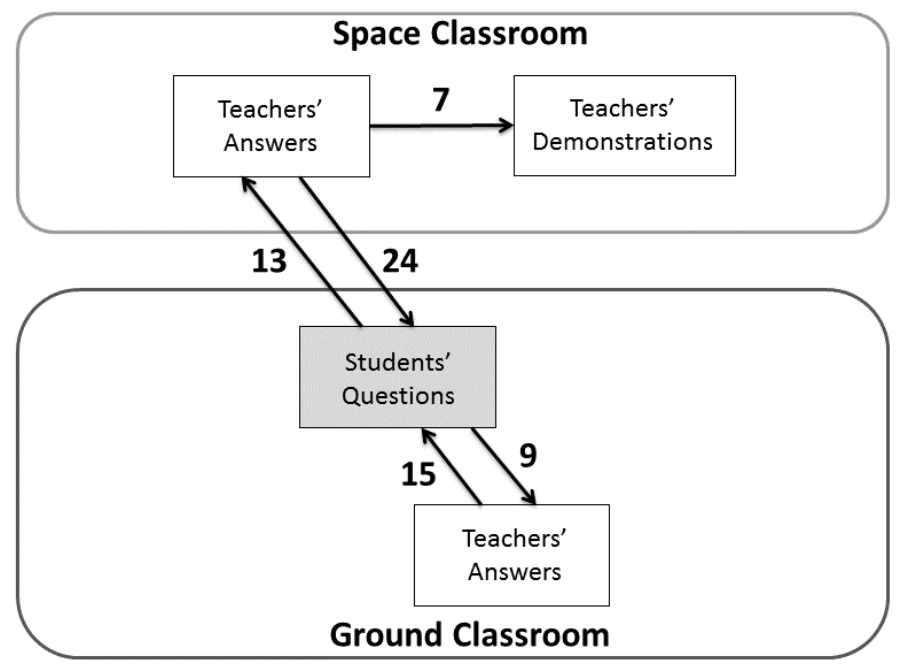

Figure 2: Instructional structure of the American space lesson in Challenger Center. 


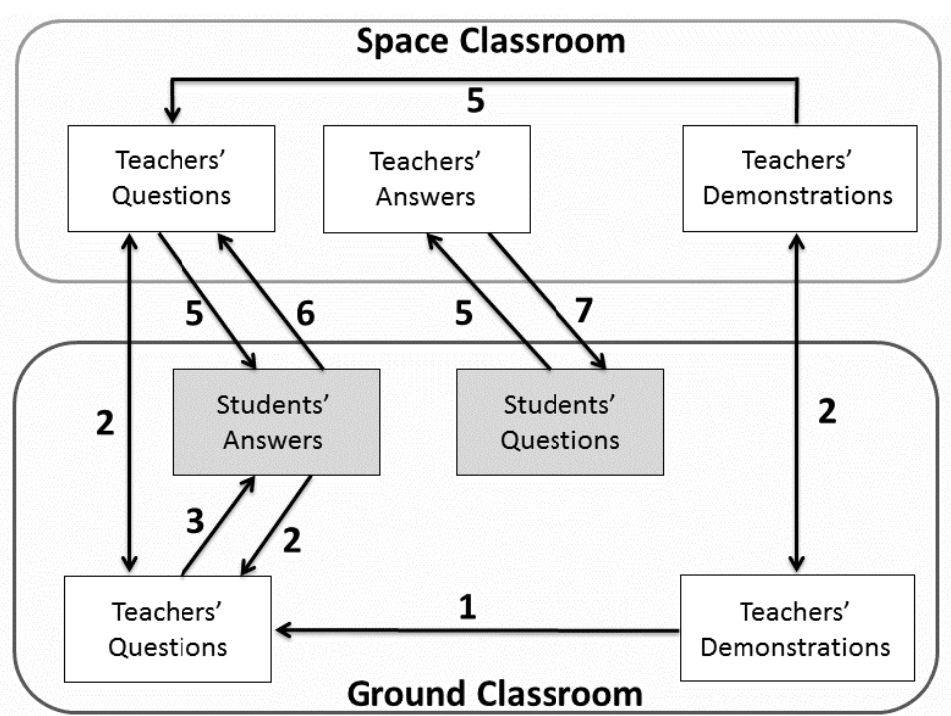

Figure 3: Instructional structure of Chinese space lesson.

\section{Classroom Discourse}

An analysis was also conducted to determine the classroom discourse among teachers and students within the Chinese and American lessons, including the percentage of words spoken by groundbased students, by ground-based teachers, and by space-based astronaut teachers. In general, one of the similarities among all three lessons was that the teachers, not the students, spoke the majority of words during the lessons-only 11\% (the Chinese lesson), 10\% (the American Discovery Center lesson), and 5\% (the American Challenger Center lesson) of words spoken during the lessons were by the students. Figure 4 presents the results from the analysis of the distribution of words spoken by participants within the Chinese and American lessons, showing the ratio of student-to-teacher words spoken in each lesson.

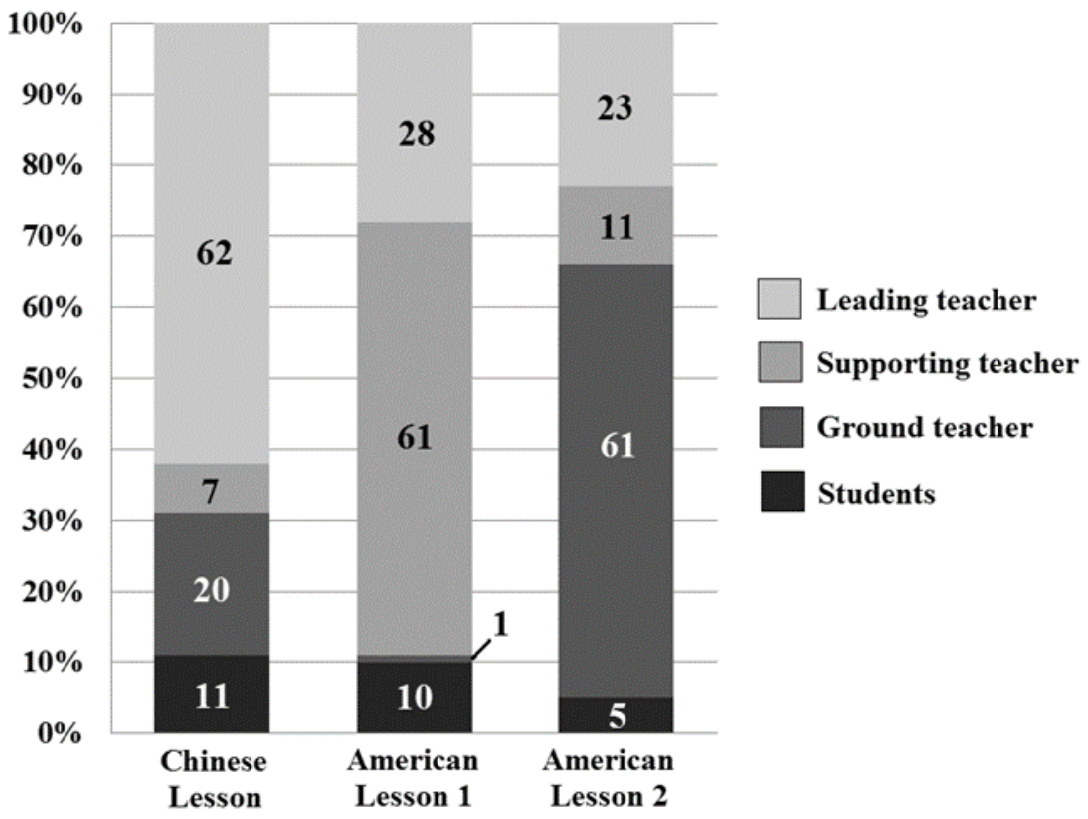

Figure 4. Distribution of words spoken by participants within the Chinese and American lessons.

Differences were identified between the Chinese and American lessons in terms of the spoken discussions among the leading space-based teacher, supporting space-based teachers, and groundbased teachers. In the Chinese lesson, the space-based teachers were the main instructors in the lesson and they contributed $69 \%$ of all the spoken words throughout the lesson. The leading space-based 
teacher in the Chinese lesson, Ms. Yaping Wang, was the key instructor in the lesson-Ms. Wang performed the demonstrations, conducted the experiments, explained the science concepts, asked the students questions, answered the students' questions, and interacted with the ground-based teachers. The two supporting space-based teachers in the Chinese lesson only had limited interacted with students. The ground-based teachers also had different roles from each other during the lesson. Specifically, one of the ground-based teachers introduced the goal of the lesson at the beginning, whereas the other ground-based teacher asked students questions to facilitate the transitions between the ground-based participants and the space-based participants. In the Chinese lesson, the groundbased teachers also helped the space-based teachers to communicate with the students by providing comparative demonstrations within the ground-based learning environment. This enabled the students to contrast the results from the ground-based demonstrations with the results from the demonstrations offered by the space-based astronaut-teachers in the micro-gravity environment.

Of the lessons analyzed, the American lesson conducted at the Discovery Center contained the highest percentage (89\%) of space-based astronaut-teachers speaking the words presented throughout the lesson. However, unlike the Chinese lesson where the lead astronaut-teacher dominated the conversation, in the American Discovery Center lesson all three of the supporting space-based astronaut-teachers contributed about equally as the lead astronaut-teacher by taking turns answering students' questions and providing demonstrations in the Endeavour space shuttle. Another aspect of the American Discovery Center lesson was that the ground-based teachers did not have any interactions with either the students or the space-based astronaut-teachers throughout the instruction. In the American lesson at the Challenger Center, the space-based astronaut-teachers contributed on $34 \%$ percentage of the words spoken throughout the lesson, while the ground-based teachers contributed $61 \%$ of the words spoken during the instruction. Another aspect of the American Challenger Center lesson was that in the beginning of the lesson the two ground-based teachers each provided introductory lectures to the students about the instruction. Also in the American Challenger Center lesson, during the first half of the lesson the space-based astronaut-teachers answered questions that the students posed, but then in the second half of the lesson it was the ground-based teachers that answered questions posed by the students.

\section{Science Topics Coverage and Pedagogy}

Results from the data analysis showed that the instructors in the three lessons covered a total of 40 specific science topics, conducted nine experiments or demonstrations in the space-based environment, and applied multiple pedagogical methods. In general, the two American lessons covered more science topics than the Chinese lesson; however, the Chinese lesson involved more experiments and demonstrations than the two American lessons. Furthermore, as discussed earlier, the instructors in the Chinese lesson utilized more multifaceted pedagogical methods than the instructors in the two American lessons.

Science topics coverage. Within the lessons, the most popular theme for science topics presented was Health and Life in Space. Science topics related to this theme were covered 26 times in total within the three lessons, including 14 times when verbal explanations were augmented with visual representations, and 12 times employing only verbal explanations with no corresponding visual representations. Within the Health and Life in Space theme, exercising in space was the only science topic that was mentioned across all three lessons, while seven topics (e.g., feeling of weightlessness in space, eating space food, wearing a space suit, sleeping in space, and drinking in space) were covered in two lessons. Three topics (e.g., water recycling and space debris) were only covered in the Chinese lesson, and four topics (e.g., tracking time in space and adapting to space) were only covered in the American lessons. 
Another main theme that all three lessons covered was Work and Career in Space, with topics related to this theme presented 19 times in total among the three lessons. Different from the Health and Life in Space theme wherein many topics were presented employing verbal descriptions and visual representations, most topics in the theme of Work and Career in Space were presented through just verbal descriptions, and only one topic (i.e., function of cabins in space shuttle) in this theme was explained in the Chinese lesson employing visual representations. There was limited overlap in topics coverage between the Chinese and American lessons-specifically, astronaut training and responsibilities during the mission were the only two science topics in this theme that were mentioned in both the Chinese and American lessons. Nine topics (e.g., mission to mars, making mistakes in space mission, childhood career aspirations, and procedure for becoming astronauts) were only presented in the American lessons, while one topic (e.g., function of cabins in space shuttle) only appeared in the Chinese lesson.

The third main theme was Exploration in Space and Earth Science, with topics related to this theme presented 16 times in total among the three lessons. The topics that the instructors discussed within this theme were mostly presented verbally without visual representations, and there was only very limited overlapping of topics coverage found between the Chinese lesson and American lessons. For example, stars and constellations along with earth and space shuttle orbit were the only two topics that both the Chinese and American lessons covered, and earth and space shuttle orbit was the only topic that was explained using visual representations (i.e., in the American Discovery Center lesson). Unidentified flying objects was a topic only presented in the Chinese lesson, and heating from the sun in space and observation of global warming were two topics only presented in the American lesson at Discovery Center. In addition, six topics (e.g., life on earth and other planets, telescope and photographs, biological experiments in space) were only presented in the American lesson at the Challenger Center. Table 3 presents the results from the analysis of science topics covered in the Chinese and American space lessons.

Table 3.Science Topics Covered in the Chinese and American Space Lessons

\begin{tabular}{|c|c|c|c|c|}
\hline Themes & Specified Themes & $\begin{array}{l}\mathrm{CN} \\
\mathrm{L}\end{array}$ & $\begin{array}{l}\text { US } \\
\text { L1 }\end{array}$ & $\begin{array}{l}\text { US } \\
\text { L2 }\end{array}$ \\
\hline \multirow{20}{*}{$\begin{array}{l}\text { Health and } \\
\text { Life in Space }\end{array}$} & Clean air in shuttle & & ++ & \\
\hline & Eating space food & ++ & & ++ \\
\hline & Wearing space suit & ++ & & ++ \\
\hline & Sleeping in space & ++ & & ++ \\
\hline & Drinking in space & ++ & ++ & \\
\hline & Bicycle riding in space & ++ & ++ & \\
\hline & Techniques for preventing microgravity harms & + & + & \\
\hline & Preparation for microgravity & + & ++ & \\
\hline & Water recycling & + & & \\
\hline & Space debris & + & & \\
\hline & Exercise equipment in space & + & ++ & + \\
\hline & Feeling of weightlessness in space & & + & + \\
\hline & Sense of direction in space & + & & \\
\hline & Brushing teeth in space & & & ++ \\
\hline & Tracking time in space & & & + \\
\hline & Adapting to space & & & + \\
\hline & Manipulating the robotic arm & & + & \\
\hline & Function of cabins in space shuttle & ++ & & \\
\hline & Preparations for spacewalk & & + & + \\
\hline & Connection between space shuttle and space station & & & + \\
\hline
\end{tabular}




\begin{tabular}{|c|c|c|c|c|}
\hline \multirow{8}{*}{$\begin{array}{l}\text { Work } \\
\text { Career } \\
\text { Space }\end{array}$} & Mission to mars & & & + \\
\hline & Making mistakes during space missions & & & + \\
\hline & Childhood career aspirations & & + & + \\
\hline & Selection of being spacewalk astronauts & & + & + \\
\hline & Procedure for becoming astronauts & & + & + \\
\hline & Astronaut training & + & + & + \\
\hline & Career relevance between teacher and astronaut & & + & \\
\hline & Responsibilities in the mission & + & + & \\
\hline \multirow{12}{*}{$\begin{array}{l}\text { Exploration in } \\
\text { Space and } \\
\text { Earth Science }\end{array}$} & Unidentified flying objects (UFO) & + & & \\
\hline & Stars and constellations & + & + & + \\
\hline & Earth and space shuttle orbit & + & ++ & \\
\hline & Heating from the sun in space & & + & \\
\hline & Preparation for the mission & & + & + \\
\hline & Observation of global warming & & + & \\
\hline & Life on Earth and other planets & & & + \\
\hline & Telescopes and photographs & & & + \\
\hline & Biological experiments in space & & & + \\
\hline & Orbit and speed of shape shuttle & & & + \\
\hline & Rocket lunching process & & & + \\
\hline & Hyper-gravity during lunching & & & + \\
\hline
\end{tabular}

Note:

No marking indicates the topic was not mentioned in the lesson;

+ marking indicates the topic was verbally explained with no visual representations;

++ marking indicates the topic was introduced with visual representations and verbal explanation.

Science experiments presented. Within the three lessons, the space-based astronaut-teachers in the micro-gravity environment conducted a total of nine science experiments. In general, the Chinese space-based astronaut-teachers presented more science experiments than the American space-based astronaut-teachers. The Chinese astronaut-teachers also employed a more multifaceted instructional strategy, offering comparisons between the results from experiments performed by the astronautteachers in the space-based environment with the results from versions performed by the groundbased teachers. Three of the experiments (i.e., lifting and floating in space, making water membranes, and making water bubbles) were demonstrated in both the Chinese and American lessons. In the experiments about lifting and floating in space, both the Chinese and American space-based astronaut-teachers presented a variety of their floating poses in the space shuttle and lifted their colleagues as demonstrations of micro-gravity phenomena in the space environment. In the two experiments related to water, both the Chinese and American space-based astronaut-teachers presented activities employing liquid surface tension to demonstrate how in the outer space microgravity environment, a water drop can be stretched into a large water membrane and then inflated into a water bubble.

Although the space-based astronaut-teachers in the two American lessons conducted a total of seven experiments in the micro-gravity environment, there were several demonstrations included in the American lessons that were not incorporated in the Chinese lessons, including: (a) projectile motion, in which a space-based astronaut-teacher (presenting for the Discovery Center lesson) threw a baseball in several different directions in the micro-gravity environment; (b) floating items attaching, in which the space-based astronaut-teacher (presenting for the Discovery Center) used spinning baseballs to demonstrate how objects move in space and how two moving items can be synchronized; and (c) paper airplane flying, in which the space-based astronaut-teacher (presenting 
for the Challenger Center) demonstrated how paper airplanes failed to fly in the micro-gravity environment because of the limited air lift force available to support the paper airplane.

Table 4:Science Experiments Conducted in the Chinese and American Space Lessons

\begin{tabular}{|c|c|c|c|c|c|}
\hline & Science Experiment Themes & Scientific Laws and Theories & $\mathrm{CN}$ & US & US \\
\hline & & & & L1 & L2 \\
\hline \multirow{3}{*}{$\begin{array}{l}\text { Gravity } \\
\text { and } \\
\text { Projectile Motion }\end{array}$} & Lifting and floating in space & Newton's first law of motion & * & * & * \\
\hline & Mass measurement in space & Newton's second law of motion & *** & & \\
\hline & Projectile motion & Newton's second law of motion & & ** & \\
\hline \multirow{3}{*}{$\begin{array}{l}\text { Rotation } \\
\text { and } \\
\text { Circular Motion }\end{array}$} & Gravity pendulum operations & Centripetal force & $* * *$ & & \\
\hline & Floating items synchronizing & Centrifugal force & & & * \\
\hline & Gyroscope operations & Angular momentum conservation & *** & & \\
\hline \multirow{3}{*}{$\begin{array}{l}\text { Aerodynamics } \\
\text { and } \\
\text { Surface Tension } \\
\end{array}$} & Paper airplane flying & Lift Force & & & $*$ \\
\hline & Making water membranes & Liquid surface tension & * & * & \\
\hline & Making water bubbles & Liquid surface tension & * & * & \\
\hline $\begin{array}{l}\text { Note: } \\
\text { No marking ind } \\
{ }^{*} \text { marking indica } \\
{ }_{* *} \text { marking indic }\end{array}$ & $\begin{array}{l}\text { tes there was no demonstrati } \\
\text { s space demonstrations with } \\
\text { es demonstrations in space w }\end{array}$ & $\begin{array}{l}\text { comparative demonstrations; } \\
\text { comparative demonstrations i }\end{array}$ & & & \\
\hline
\end{tabular}

Space-based astronaut-teachers in the Chinese lessons conducted a total of six experiments in the micro-gravity environment, of which there were several that were not incorporated in the American lessons, including: (a) mass measurement in space, (b) gravity pendulum operations, and (c) gyroscope operations. As discussed earlier, one of the distinguishing features in the Chinese lesson was that the space-based astronaut-teachers and the ground-based teachers collaborated during the experiments to demonstrate the differences between the results obtained in outer space and the results obtained on Earth. For example, when the space-based astronaut-teacher demonstrated in the micro-gravity environment the results of using a spring balance to measure a counterweight followed by operating a pendulum to generate harmonic motion, the ground teacher demonstrated the same measurement and pendulum operation activity in the standard gravity of the ground-based learning environment. More than simply comparing the physical phenomena in the micro-gravity environment versus the normal-gravity environment, the Chinese space-based astronaut-teachers also conducted experiments comparing objects with different ways of moving in the micro-gravity environment. For example, when demonstrating gyroscope operations, the space teacher prepared two sets of gyroscope (one of them was moving without the internal rotation and the other was moving with the internal rotation) with results showing that the gyroscope operations moved in irregular ways without the internal rotation. Table 4 presents the results from the analysis of science experiments conducted in the Chinese and American space lessons.

\section{Discussion}

Science education conducted in engaging, informal learning settings can provide a linkage between the science concepts studies by students in the classroom and the non-school experiences that students find personally meaningful. However, a non-trivial obstacle faced when undertaking this pedagogical approach is successfully coping with the logistical challenges posed. Informal science educators, such as the astronauts studied in this research paper, can offer students learning experiences that highlight experiments and provide corresponding verbal explanations in special environments, such as micro-gravity, to encourage students to become interested in learning about science (Brossard, Lewenstein, \& Bonney, 2005). This approach to science instruction utilizes a guided inquiry approach, which is an integral part of any science curriculum. These learning opportunitiesengage students in fundamental concepts and utilize descriptive and qualitative 
methods that are enhanced within informal settings. The explorations are designed to help students in the techniques of making observations of scientific processes and to provide real-world examples of science. Problem-solving strategies depend on conceptual understandings, and hands-on observation of simple and relatable learning opportunities help to build an understanding of scientific processes and concepts (Apple, 2014).

In this study, we performed an analysis comparing science lessons that had been taught by either Chinese or American astronauts in their respective space shuttles (e.g., the Shenzhou and the Endeavour) during their missions orbiting Earth in outer space. This study examined the selected science lessons in detail, with a focus on analyzing science teaching methodology with respect to two properties: (a) the structures of the lessons (e.g., the manner of student-teacher interactions), and (b) the science themes and topics covered during the lessons. This research builds upon previous studies that have analyzed informal science education events, usually with a focus on students' attitudinal perceptions and academic achievement (e.g., Fadigan, \&Hammrich, 2004; Jarvis \& Pell, 2005). Assessment of students' perceptions and achievement are certainly important, but much remains to be understood about how informal science educators in environments outside of the school setting can positively impact students' science learning experience. One of particular interests is the study of how specific science topics can be taught via collaborations between science teachers and field scientists working in interesting environments, such as micro-gravity or any of the other plethora non-classroom settings where scientists conduct research.

This study's findings suggest that under the non-traditional settings with engaging activities and interesting topics, informal science education can play a distinct role in providing students with experiences of: (a) experiments unavailable in classroom settings, and (b) explanations of these experiments by field-based scientists conducting original research. The analysis of the lessons sampled in this study revealed three distinct and dominant themes for how both the Chinese and the American astronauts conceptualized the science topics (i.e., Health and Life in Space, Work and Career in Space, and Exploration in Space and Earth Science). The analysis also examined how the teacher-student interactions were structured. It was determined that the lessons taught by the Chinese and the American astronauts shared several broad similarities in the manner of choosing and the method of demonstrating science concepts. Both the Chinese and American lessons covered a broad range of science topics through verbal presentations augmented by visual demonstrations. Additionally, lessons provided multiple opportunities for students to interact with astronaut-teachers by asking them questions, which stimulates interest and also heightens engagement. The science lessons taught by the Chinese and American astronaut-teachers also had several key differences, of which the most notable difference was that the Chinese lesson employed a more multifaceted lesson structure (i.e., both students and teachers asking questions, not just students asking questions) than the two American lessons analyzed.

Before proceeding to the conclusions concerning the findings from this research study, several limitations to the current study should be noted. First, because the specific lessons that fit the research scope of the current study are limited in number, only three existing lessons fitting the sampling criteria were selected for analysis. Second, the lesson analysis framework focused on the properties of the structures of the lessons and the science content coverage. As such, vital features of the lessons that would be viewable from other perspectives may have been missed. However, even with these limitations, this study provided an opportunity to take a glimpse at how science content can be presented and conceptualized by informal science educators in unusual, informal learning environments. The primary goal of this study was not to determine the best lesson, but instead to examine the potential educational methods and opportunities for implementing innovative informal science education that augments the formal classroom curriculum. 


\section{Conclusion and Educational Implication}

The differences identified between the Chinese and the American lessons reflect varying emphases of the numerous educational opportunities afforded by teaching science in the micro-gravity environment of outer space. In general, the Chinese lesson included more teacher directed activities and the American lesson included more student directed activities. This is perhaps because China has a nationally centralized curriculum, and it was decided by their governing board that the science lessons taught should be designed to fit the broadest range of grades possible across the K-12 spectrum. On the other hand, the two American lessons were designed to address a more narrow range of middle and high school students. Additionally, differences between the Chinese and American lessons in regards to scientific experiments, laboratory equipment, and space equipment presented indicated dissimilar pedagogical priorities-the Chinese lesson emphasized helping students conceptualize the laws of physics through demonstrations of micro-gravity experiments, whereas the American lessons emphasized astronauts answering the students' questions via spacethemed anecdotes about their professional experiences and demonstrations of micro-gravity experiments. Furthermore, the differing roles for the ground-based teachers combined with the differing structures of the Chinese and American lessons indicated dissimilar pedagogical designsthe American lessons emphasized the use of a question-and-answer between the ground-based students and the space-based astronaut-teachers for presenting the science content; whereas the Chinese lesson employed the ground-based teachers as assistants to facilitate the space-based astronaut-teachers' instruction. For example, while the Chinese space-based astronaut-teachers were conducting experiments in the micro-gravity environment, the ground-based teachers demonstrated the same experiment in the standard-gravity environment so the students could witness the comparison.

Science is not just a body of facts that can be memorized and then repeated on an exam. Sadly, science instruction has become just that (Conderman \& Woods, 2008; Bybee \& Van Scotter, 2007). It is in the "doing" rather than the "seeing" of science that the designers of this educational effort hope to instill in others and communicate a love of the scientific discipline and a sense of appreciation toward scientific advancement. The PBL approach utilized that integrates computer modeling is one example of a system science curriculum that offers students the opportunity to engage in hands-on activities, problem solving exercises, and collaborative group work (Robertson, 2009). With a goal of instilling environmental stewardship via constructivist instructional methods, the hope is that the result will be an increased awareness and understanding of polar science. And, through the training of many students from groups traditionally underrepresented in the sciences, the project team seeks to create a new generation of role models in the polar sciences.

To summarize, the study presented in this article examined a sample of informal science lessons codeveloped by formal and informal science educators, and which were utilized as an alternative approach for helping students to understand science concepts and become engaged in learning science. Although this study did not have access to any direct assessments of the participating students' learning outcomes, nonetheless the lessons were examined to investigate the pedagogical structures and science content covered that were included by the educators, and it was determined that these findings have implications for determining future directions for research and practice of innovative informal science education. In our contemporary digital era, there are fewer boundaries than ever before for education. Beyond the traditional schoolhouse curriculum, there are opportunities for out-of-classroom settings such as parks, museums, oceans, and space centers, to all be utilized as meaningful and engaging settings for contextualizing and connecting science curriculum content to the real life, non-school experiences of students. This situation calls for pioneering STEM educators to (re)consider the potential educational opportunities available for teaching science content in a manner that encourages students to understand that science is not a dry, 
academic discipline; but rather science is a living, thriving system whose corresponding foundational education benefits greatly from its connections with informal learning settings and other experiences that complement the school curriculum. The analysis presented in this study examined instructional patterns within the informal learning environments sampled, and the findings suggest that science education researchers and practitioners would benefit from: (a) inviting field-based science professionals to serve as informal educators delivering content specialized based upon their professional occupations, (b) designing learning modules that utilize engaging, non-classroom learning environments that contextualize concepts for students, and (c) fostering collaboration between formal science school teachers and compatible informal science educators.

\section{References}

An, S. (2008). Outsiders' views on Chinese mathematics education: A case study on the U.S. teachers' teaching experience in China. Journal of Mathematics Education, 1(1), 1-27.

An, S., Kulm, G., \& Wu, Z. (2004). The pedagogical content knowledge of middle school mathematics teachers in China and the US. Journal of Mathematics Teacher Education, 7(2), 145-172.

Apple, M. W. (2014). Official knowledge: Democratic education in a conservative age. New

York: Routledge.

Boutte, G., Kelly-Jackson, C., \& Johnson, G. L. (2010). Culturally relevant teaching in science classrooms: Addressing academic achievement, cultural competence, and critical consciousness. International Journal of Multicultural Education, 12(2), 1-19.

Braund, M., \& Reiss, M. (2006). Towards a more authentic science curriculum: The contribution of out-of-school learning. International Journal of Science Education, 28(12), 1373-1388.

Brossard, D., Lewenstein, B., \& Bonney, R. (2005). Scientific knowledge and attitude change: The impact of a citizen science project. International Journal of Science Education, 27(9), 1099-1121.

Cai, J., \& Lester Jr, F. K. (2005). Solution representations and pedagogical representations in Chinese and US classrooms. The Journal of Mathematical Behavior, 24(3), 221-237.

Cai, J., Lo, J. J., \& Watanabe, T. (2002). Intended treatments of arithmetic average in US and Asian school mathematics textbooks. School Science and Mathematics, 102(8), 391-404.

Charalambous, C. Y., Delaney, S., Hsu, H. Y., \& Mesa, V. (2010). A comparative analysis of the addition and subtraction of fractions in textbooks from three countries. Mathematical Thinking and Learning, 12(2), 117-151.

Chen, C., \& Stevenson, H. W. (1995). Motivation and mathematics achievement: a comparative study of Asian-American, Caucasian-American, and East Asian high school students. Child Development, 66(4), 1215-1234.

Clarke, D.J., Keitel, C., \& Shimizu, Y. (Eds.) (2006). Mathematics classrooms in twelve countries: the insider's perspective. Rotterdam: Sense Publishers.

Correa, C. A., Perry, M., Sims, L. M., Miller, K. F., \& Fang, G. (2008). Connected and culturally embedded beliefs: Chinese and US teachers talk about how their students best learn mathematics. Teaching and Teacher Education, 24(1), 140-153.

DeWitt, J., \&Storksdieck, M. (2008). A short review of school field trips: Key findings from the past and implications for the future. Visitor Studies, 11(2), 181-197.

Donovan, B. (2002). An illustration of practice in search of theory. Theory and Practice, 41, 17-26.

Eshach, H. (2007). Bridging in-school and out-of-school learning: Formal, non-formal, and informal education. Journal of Science Education and Technology,16(2), 171-190.

Fadigan, K. A., \&Hammrich, P. L. (2004). A longitudinal study of the educational and career trajectories of female participants of an urban informal science education program. Journal of Research in Science Teaching, 41(8), 835-860.

Falk, J. H., \&Storksdieck, M. (2010). Science learning in a leisure setting. Journal of Research in Science Teaching, 47(2), 194-212.

Faria, C., Pereira, G., \&Chagas, I. (2012). D. Carlos de Bragança, a pioneer of experimental marine oceanography: Filling the gap between formal and informal science education. Science \& Education, 21(6), 813-826.

Griffin, J. (2004). Research on students and museums: Looking more closely at the students in school groups. Science Education, 88(S1), S59-S70.

Gutwill, J. P., \& Allen, S. (2012). Deepening students' scientific inquiry skills during a science museum field trip. Journal of the Learning Sciences, 21(1), 130-181.

Haden, C. A., Jant, E. A., Hoffman, P. C., Marcus, M., Geddes, J. R., \& Gaskins, S. (2014). Supporting family conversations and children's STEM learning in a children's museum. Early Childhood Research Quarterly, 29(3), 333-344.

Hasslen, Robin. (2008). From a tarpaper shack to a transformed classroom: A teacher's journey. Kappa Delta Pi Record, 44, 52-54.

Jarvis, T., \& Pell, A. (2005). Factors influencing elementary school children's attitudes toward science before, during, and after a visit to the UK National Space Centre. Journal of Research in Science Teaching, 42(1), 53-83.

Jones, A. C., Scanlon, E., \& Clough, G. (2013). Mobile learning: Two case studies of supporting inquiry learning in informal and semiformal settings. Computers \& Education, 61, 21-32.

Lan, X., Legare, C. H., Ponitz, C. C., Li, S., \& Morrison, F. J. (2011). Investigating the links between the subcomponents of executive function and academic achievement: A cross-cultural analysis of Chinese and American preschoolers. Journal of Experimental Child Psychology, 108(3), 677-692. 
Osborne, Jonathan, Simon, Shirley and Collins, Sue (2003). Attitudes towards science: a review of the literature and its implications, International Journal of Science Education, 25:9, 1049 - 1079.

Palmer, P.J. (1998). The courage to teach: Exploring the inner landscape of a teacher's life. San Francisco: Jossey-Bass.

Palmquist, S., \& Crowley, K. (2007). From teachers to testers: How parents talk to novice and expert children in a natural history museum. Science Education, 91(5), 783-804.

Roth, K., \&Garnier, H. (2006). What science teaching looks like: An international perspective. Educational Leadership, 64(4), 16.

Schiele, B. (1995). The non-formal communication of scientific knowledge. Prospects, 25(1), 87-99.

Scribner, S., \& Cole, M. (1973). Cognitive consequences of formal and informal education. Science, 182(4112), 553-559.

Stigler, J. W., \& Perry, M. (1988). Mathematics learning in Japanese, Chinese, and American classrooms. New Directions for Child and Adolescent Development, 41, 27-54.

Tran, L. U. (2007). Teaching science in museums: The pedagogy and goals of museum educators. Science Education, 91(2), 278297.

Wang, J., \& Lin, E. (2005). Comparative studies on US and Chinese mathematics learning and the implications for standardsbased mathematics teaching reform. Educational researcher, 34(5), 3-13.

Robertson, W.H. (2009). Dr. Skateboard's action science: Teaching physics in context.The science education review, 8(1), 30-34.

Robertson, W. H., \& Lesser, L. (2013). Scientific skateboarding and mathematical music: edutainment that actively engages middle school students. European journal of science and mathematics education, 1(2), 60-68. 